\title{
Mineralization of LCFA Associated With Anaerobic Sludge: Kinetics, Enhancement of Methanogenic Activity, and Effect of VFA
}

\author{
M. A. Pereira, D.Z. Sousa, M. Mota, M. M. Alves \\ Centro de Engenharia Biológica, Universidade do Minho, 4710-057 Braga, \\ Portugal; telephone: +351.253604402; fax: +351.253678986; \\ e-mail: madalena.alves@deb.uminho.pt
}

Received 19 February 2004; accepted 16 July 2004

Published online 30 September 2004 in Wiley InterScience (www.interscience.wiley.com). DOI: 10.1002/bit.20278

\begin{abstract}
Long-chain fatty acids (LCFA) associated with anaerobic sludge by mechanisms of precipitation, adsorption, or entrapment can be biodegraded to methane. The mineralization kinetics of biomass-associated LCFA were established according to an inhibition model based on Haldane's enzymatic inhibition kinetics. A value around $1,000 \mathrm{mg} \mathrm{COD}-\mathrm{LCFA} \cdot \mathrm{g} \mathrm{VSS}{ }^{-1}$ was obtained for the optimal specific LCFA content that allowed the maximal mineralization rate. For sludge with specific LCFA contents of $2,838 \pm 63$ and $4,571 \pm 257 \mathrm{mg} \mathrm{COD-LCFA.g} \mathrm{VSS}{ }^{-1}$, the specific methanogenic activities in the presence of acetate, butyrate, and $\mathrm{H}_{2} / \mathrm{CO}_{2}$ were significantly enhanced after the mineralization of the biomass-associated LCFA. For sludge with a specific LCFA content near the optimal value defined by the kinetic model, the effect of adding VFA to the medium was studied during the mineralization of the biomass-associated LCFA. Different patterns were obtained for each individual substrate. Acetate and butyrate were preferentially consumed by the consortium, but in the case of propionate no evidence of a sequential consumption pattern could be withdrawn. It was concluded that LCFA do not exert a bactericidal neither a permanent toxic effect toward the anaerobic consortia. A discussion is addressed to the relative roles of a reversible inhibitory effect and a transport limitation effect imposed by the LCFA surrounding the cells. (c) 2004 Wiley Periodicals, Inc.
\end{abstract}

Keywords: LCFA; oleic acid; methanogenic activity; kinetics

\section{INTRODUCTION}

Lipids, abundant in slaughterhouses, edible oil/fat refineries, and dairy wastewaters, are potentially attractive for biogas production due to their high theoretical methane yield. However, in practice, physicochemical pretreatment is usually applied before anaerobic treatment, because neutral fats are easily hydrolyzed to long-chain fatty acids

Correspondence to: M. M. Alves

Contract grant sponsors: Fundação para a Ciência e Tecnologia (FCT); Fundo Social Europeu (FSE)

Contract grant numbers: PRAXIS XXI/BD/20326/99; SFRH/BD/ $8726 / 2002$
(LCFA), which are reported to exert an acute toxic effect on the microorganisms involved in the $\beta$-oxidation and methanogenic pathways (Angelidaki and Ahring, 1992; Hwu, 1997; Koster and Cramer, 1987; Rinzema, 1988).

In general, a severe toxic effect is referred, although granular sludge seems to be more resistant to LCFA toxicity than suspended sludge (Hwu, 1997). Rinzema (1988) reported that LCFA exert a bactericidal effect and that acetoclastic bacteria do not adapt to LCFA either upon repeated exposure to toxic concentrations or after prolonged exposure to nontoxic concentrations. The recovery after a lag phase usually observed in batch assays was attributed by this author to the growth of few survivors. Angelidaki and Ahring (1992) reported a permanent toxic effect that underlines the conclusions of Rinzema (1988). According to some authors, the mechanism of LCFA toxicity seems to be related to the adsorption of the surface active acids onto the cell wall, which affects its transport and/or protective functions (Demeyer and Henderickx, 1967; Galbraith et al., 1971; Rinzema, 1988). More recently, Lalman and Bagley (2001) reported the inhibitory effects of oleic and stearic acids to acetoclastic and hydrogenophilic methanogens. In their study, diethyl ether was added at a concentration of $14.2 \mathrm{~g} \mathrm{~L}^{-1}$, to promote LCFA dispersion in the cultures, being a questionable approach, since this compound is not expected to occur under real conditions.

More than inhibition drawbacks, flotation, and washout are reported to be important problems associated to the adsorption of LCFA onto anaerobic sludge, as granulation and/or granule maintenance are difficult tasks for lipid/ LCFA-containing wastewaters. Hwu (1997) added some insights to this phenomenon by assessing the critical LCFAspecific organic load that induced flotation and complete washout during the operation of expanded granular sludge bed (EGSB) reactors, concluding that it corresponded to a concentration far below the toxicity limit.

Problems of sludge flotation or unsuccessful granulation were ascribed to treatment failure of industrial- and pilot-scale UASB reactors treating lipids/LCFA-containing 
wastewater (Hawkes et al., 1995; Hwu, 1997; Rinzema, 1988; Samson et al., 1985; Sam-soon et al., 1991). Reasonable solutions to overcome flotation problems were searched in some reported works: sieve drums, biomass recirculation, or partial phase separation were tentatively applied for that purpose (Beccari et al., 1998; Hamdi et al., 1992; Hwu, 1997; Rinzema, 1988), without convincing reliability.

In recent studies conducted by our research group, it was observed that anaerobic sludge was able to mineralize LCFA in amounts up to $3 \mathrm{~g} \mathrm{COD} \cdot \mathrm{g} \mathrm{VSS}^{-1}$, provided that it was associated with the sludge, not the bulk medium, evidencing that the anaerobic consortium remained active in such conditions (Pereira et al., 2002, 2003). This clearly contradicts the generally accepted idea that LCFA adsorption onto anaerobic sludge is closely linked to LCFA inhibition through mechanisms of cell membrane/wall damage, eventually inducing cytolysis and bactericidal effects (Demeyer and Henderickx, 1967; Galbraith et al., 1971). Salminen et al. (2001) observed the batch biodegradation of accumulating materials (mainly LCFA) in anaerobic digesters that previously failed the operation, during the semicontinuous treatment of poultry slaughterhouse waste.

These previous results prompted a renewed interest for a more deep study on the anaerobic biodegradation of LCFA that are mainly associated to the biomass, aiming to optimize its degradation rate. In this regard, the objectives of the present work are:

(1) to establish the kinetics of anaerobic mineralization of the biomass-associated LCFA;

(2) to evaluate and define the limits of methanogenic activity enhancement after the mineralization of the biomass-associated LCFA; and

(3) to evaluate the effect of individual Volatile Fatty Acids (VFA) on the mineralization of the biomass-associated LCFA.

Oleic acid was used as a model for LCFA to obtain the loaded sludge in the continuous reactor operation because it is, in general, the most abundant of all LCFA present in wastewater (Komatsu et al., 1991), has a good sol- ubility, and is one of the more toxic LCFA (Galbraith et al., 1971).

\section{MATERIALS AND METHODS}

\section{Sludge Sources}

Anaerobic sludge, in a total of 38 samples, was obtained from continuous laboratory-scale reactors operated at mesophilic conditions $\left(37^{\circ} \mathrm{C}\right)$ with oleic acid as substrate. Table I presents the operating conditions prevailing at the moments of sample collection. The fixed bed reactor configuration was designed to allow the sampling of entrapped biomass along the operation (Alves et al., 1998). Prior to characterization, all the sludge samples collected were washed and centrifuged $(1681 \mathrm{~g}, 10 \mathrm{~min})$ twice, with the same anaerobic basal medium used in the batch experiments. The volatile suspended solids content (VSS) of each sample was determined according to Standard Methods (1989).

\section{Sludge Characterization}

\section{Microscopic Observations}

Phase contrast microscopy was performed with a Zeiss (Oberkochen, Germany) Axioscop microscope. The same microscope was used to visualize the autofluorescence of the methanogenic consortium (420 nm).

Staining of lipid compounds was performed using Sudan black B, according to the procedure described by Seviour and Blackall (1999). An aliquot of a sludge sample was placed on a gelatin-covered slide, air dried, and immersed on a Sudan black B alcoholic solution $(0.3 \% \mathrm{wt} / \mathrm{vol}$ in ethanol $60 \%$ ) for $10 \mathrm{~min}$, followed with a 1-s rinse with water. After the excess water was removed, the slide was immersed in a safranin $\mathrm{O}$ aqueous solution $(0.5 \% \mathrm{wt} / \mathrm{vol})$ for $10 \mathrm{~s}$. It was then well rinsed with water and allowed to dry prior to examination under bright field, using a Zeiss Axioscop microscope. A control procedure was performed to remove the lipid matter by keeping the samples in con-

Table I. Sources of the anaerobic suspended sludge used in this work.

\begin{tabular}{|c|c|c|c|c|c|c|}
\hline Reactor type & Operation mode & $\begin{array}{l}\text { Influent COD } \\
\quad\left(\mathrm{mg} \mathrm{L}^{-1}\right)\end{array}$ & HRT (day) & Type of substrate ${ }^{a}$ & $\begin{array}{l}\text { Oleate loading rate } \\
\left(\mathrm{kg} \mathrm{COD} \mathrm{m}^{-3} \cdot \mathrm{day}^{-1}\right)\end{array}$ & Reference \\
\hline Fixed bed & Steady state & 12,000 & 1.4 & $\mathrm{SM}(50 \% \mathrm{COD})+\mathrm{SO}(50 \% \mathrm{COD})$ & 4.3 & Alves et al., 2001 \\
\hline Fixed bed & Steady state & 12,000 & 1.4 & SO $(100 \%$ COD $)$ & 8.6 & Alves et al., 2001 \\
\hline Fixed bed & Organic shock ${ }^{\mathrm{b}}$ & 20,000 & 0.67 & $\mathrm{SM}(50 \% \mathrm{COD})+\mathrm{SO}(50 \% \mathrm{COD})$ & 15 & Cavaleiro et al., 2001 \\
\hline Fixed bed & Hydraulic shock ${ }^{\mathrm{c}}$ & 4,000 & 0.13 & $\mathrm{SM}(50 \% \mathrm{COD})+\mathrm{SO}(50 \% \mathrm{COD})$ & 15 & Cavaleiro et al., 2001 \\
\hline EGSB & Steady state & 4,000 & 1.0 & $\mathrm{SM}(50 \% \mathrm{COD})+\mathrm{SO}(50 \% \mathrm{COD})$ & 2 & Pereira et al., 2002 \\
\hline EGSB & Steady state & 4,000 & 1.0 & SO $(100 \%$ COD $)$ & 4 & Pereira et al., 2002 \\
\hline EGSB & Steady state & 6,000 & 1.0 & SO (100\% COD) & 6 & Pereira et al., 2002 \\
\hline EGSB & Steady state & 8,000 & 1.0 & SO (100\% COD) & 8 & Pereira et al., 2002 \\
\hline
\end{tabular}

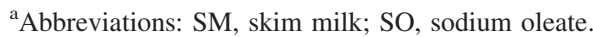

${ }^{\mathrm{b}}$ Seven samples were taken during 4 days.

${ }^{\mathrm{c}}$ Ten samples were taken during 4 days.
} 
tact, for $1 \mathrm{~h}$ at room temperature, with a solution consisting of chloroform and methanol $(2: 1, \mathrm{vol} / \mathrm{vol})$ with addition of $1 \% \mathrm{HCl}$ and $4 \% \mathrm{H}_{2} \mathrm{O}$ (High, 1984).

Scanning electron microphotographs were obtained in a Leica S360 microscope (Leica, Cambridge, England). Samples were fixed with $3 \%$ (wt/vol) glutaraldehyde solution in cacodylate buffer, $\mathrm{pH} 7.2$, and dehydrated with ascending concentration ethanol solutions $(10 \%, 25 \%, 50 \%$, $75 \%, 90 \%$, and $100 \%$ ). Prior to microscopic examination, samples were sputter-coated with gold.

\section{Methanogenic Activity Measurements}

Specific methanogenic activity (SMA) tests were performed using a pressure transducer technique (Coates et al., 1996; Colleran et al., 1992). The pressure increase developed in the batch vials fed with nongaseous substrates (30 $\mathrm{mM}$ acetate, $30 \mathrm{mM}$ propionate, and $15 \mathrm{mM}$ butyrate) or pressure decrease in vials previously pressurized (1 bar) with gaseous substrates $\left(\mathrm{H}_{2} / \mathrm{CO}_{2}, 80: 20 \mathrm{vol} / \mathrm{vol}\right)$ was monitored, using a hand-held pressure transducer capable of measuring a pressure variation of 2 bar $(0$ to $\pm 202.6 \mathrm{kPa})$ over a device range of -200 to $+200 \mathrm{mV}$, with a minimum detectable variation of 0.005 bar, corresponding to $0.05 \mathrm{~mL}$ of biogas in a $10-\mathrm{mL}$ headspace. The basal medium used in all batch experiments was made up with demineralized water, was composed of cysteine- $\mathrm{HCl}\left(0.5 \mathrm{~g} \mathrm{~L}^{-1}\right)$ and sodium bicarbonate $\left(3 \mathrm{~g} \mathrm{~L}^{-1}\right)$, the $\mathrm{pH}$ was adjusted to 7.0-7.2 with $8 \mathrm{~N} \mathrm{NaOH}$, and was prepared under strict anaerobic conditions. Methane content of the biogas was measured by gas chromatography using a Chrompack Haysep Q (80100 mesh) column (Chrompack, Les Ulis, France), with $\mathrm{N}_{2}$ as carrier gas at $30 \mathrm{~mL} \min ^{-1}$ and a flame-ionization detector. Temperatures of the injection port, column, and flame-ionization detector were 120,40 , and $130^{\circ} \mathrm{C}$, respectively. The values of methane production were corrected for the standard temperature and pressure conditions (STP). Blank controls were used for liquid substrates (no added substrate) and for gaseous substrates (pressurized with $\mathrm{N}_{2}$ / $\mathrm{CO}_{2}, 80: 20 \mathrm{vol} / \mathrm{vol}$ at $1 \mathrm{bar}$ ). All batch experiments were performed in triplicate. SMA values were determined dividing the initial slope of the methane production curve by the VSS content of each vial at the end of the experiment and were expressed in $\mathrm{mL} \mathrm{CH}_{4} \cdot \mathrm{g} \mathrm{VSS}^{-1}$. day ${ }^{-1}$, which were then converted to the equivalent chemical oxygen demand (COD). Background methane production due to the residual substrate was discounted. Ideally, the VSS values used to express the specific methanogenic activity should be the VSS initially present in the vials. However, those values account for all organic matter, including not only the cells but also the biomass-associated LCFA. To obtain the VSS content that accounts only for the cells, the methane production in the test vials was followed until stabilization in order to minimize the LCFA contribution to the VSS measured at the end of the test. These VSS values were considered for the specific methanogenic activity measurements and ideally they should be between 2 and $5 \mathrm{~g} \cdot \mathrm{L}^{-1}$.
This procedure may be questionable as some biomass growth can occur, underestimating the initial specific methanogenic activity. However, the error associated to this factor is certainly lower due to the slow growth rate of anaerobic biomass when compared to the huge amount of LCFA present in the sludge.

It should be noted that, concerning the SMA in the presence of indirect methanogenic substrates, the methane production rate will only be a valid measurement of the syntrophic activity on those substrates when the acetoclastic and hydrogenophilic activities are not rate limiting (Dolfing and Bloemen, 1985).

\section{Mineralization of LCFA Accumulated Onto the Sludge}

These batch assays were similar to the blank control assays described above for the measurement of SMA in the presence of liquid substrates. Each sludge sample was incubated in sealed batch vials of $25 \mathrm{~mL}$ at $37^{\circ} \mathrm{C}, 150 \mathrm{rpm}$, under strict anaerobic conditions, without any added organic carbon source, calcium, or nutrients. Only anaerobic basal medium was added. The initial methane production rate and the maximum plateau achieved were determined for each test, according to the example presented in Figure 1. In all cases, the methane production rate refers to the initial slope, even when a lag phase was observed, indicating a null value. The cumulative methane production at the end of the batch assays was considered an indirect measurement of the amount of biomass-associated LCFA. The specific LCFA content was then determined by dividing the maximum plateau achieved in the methane production curve by the VSS content of each vial at the end of the experiment and was expressed as $\mathrm{mg} \mathrm{COD}-\mathrm{CH}_{4} \cdot \mathrm{g} \mathrm{VSS}^{-1}$ (the direct measurement), as $\mathrm{mg}$ COD-LCFA.g $\mathrm{VSS}^{-1}$ (the indirect measurement) or just as $\mathrm{mg} \mathrm{COD} \cdot \mathrm{g} \mathrm{VSS}^{-1}$. The specific methane production rate was obtained by dividing the initial slope of each curve of methane production by the VSS content of each vial at the end of the experiment, and was expressed as mg COD-CH $4 \cdot \mathrm{g} \mathrm{VSS}^{-1} \cdot$ day $^{-1}$.

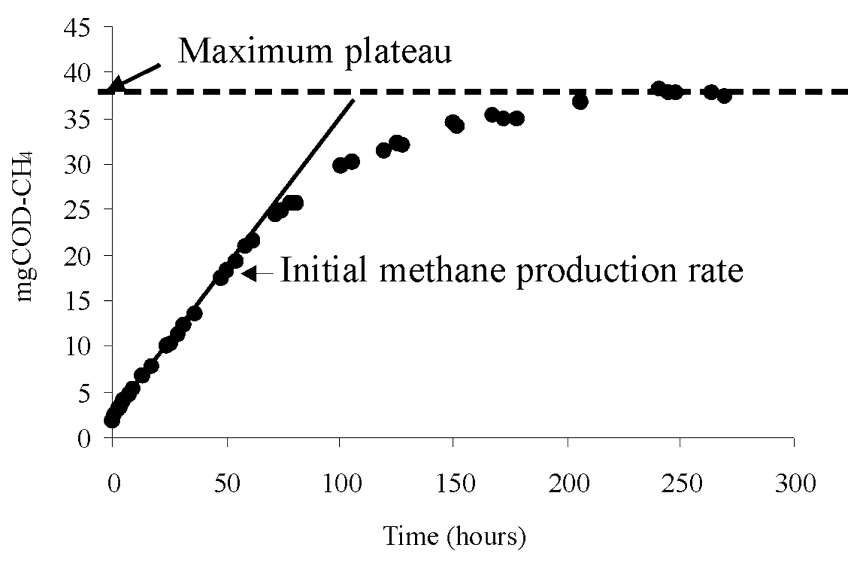

Figure 1. Example of a methane production curve in a batch assay, during the mineralization of the biomass-associated LCFA. 
Assessment of Specific Methanogenic

Activity Before and After Degrading

the Biomass-Associated LCFA

The SMA of the sludge before and after degrading the biomass-associated LCFA accumulated during the continuous operation was compared by performing parallel assays. After it had been washed with anaerobic basal medium and centrifuged $(1681 \mathrm{~g}, 10 \mathrm{~min})$ twice, the sludge was incubated in 24 vials of $25 \mathrm{~mL}$ and 12 vials of $70 \mathrm{~mL}$, at $37^{\circ} \mathrm{C}$, $150 \mathrm{rpm}$ under strict anaerobic conditions. Two sets of 18 vials $(12+6)$ were separated for parallel assays. In the first set, the methanogenic activities in acetate, propionate, butyrate and $\mathrm{H}_{2} / \mathrm{CO}_{2}$ were determined in triplicate as described before. Six vials were used as blank controls: three for liquid substrates were no substrate was added, and three for gaseous substrates where $\mathrm{N}_{2} / \mathrm{CO}_{2}(80: 20 \mathrm{vol} / \mathrm{vol})$ was pressurized ( 1 bar). In the other set of 18 vials, no substrate was added, but the degradation of the biomass-associated LCFA was followed until stabilization. The vials were then depressurized, vented with $\mathrm{N}_{2} / \mathrm{CO}_{2}(80: 20 \mathrm{vol} / \mathrm{vol})$, and methanogenic activities in acetate, propionate, butyrate, and $\mathrm{H}_{2} / \mathrm{CO}_{2}$ were measured in triplicate, as described for the first set of vials. The VSS values taken into account to calculate the specific methanogenic activity before and after the depletion of the biomass-associated LCFA were the values measured at the end of the whole experiment. Even if some error was introduced due to the possible biomass growth, this was needed to eliminate the contribution of the LCFA to the initial VSS content in the vials.

\section{Effect of Added VFA in the Mineralization of the Biomass-Associated LCFA}

In a set of vials with 500-mL working volume, the sludge containing accumulated LCFA was incubated in batch mode, keeping the environmental conditions applied in the SMA assays. Acetate, propionate, and butyrate were individually added and their depletion in the liquid phase was monitored. Possible VFA release to the medium during the mineralization of the biomass-associated LCFA was also assessed by setting blank controls where no VFA were added. VFA concentrations were determined by highperformance liquid chromatography using a Chrompack column $(300 \times 6.5 \mathrm{~mm})$ and a mobile phase of $5 \mathrm{mM}$ sulfuric acid $\left(\mathrm{H}_{2} \mathrm{SO}_{4}\right)$ at $0.7 \mathrm{~mL} \cdot \mathrm{min}^{-1}$. The column was set at $40^{\circ} \mathrm{C}$, and the detection was spectrophotometric at $220 \mathrm{~nm}$. Duplicate assays were performed.

\section{RESULTS AND DISCUSSION}

\section{Microscopic Examination of Sludge With Associated LCFA}

The ability of suspended sludge to accumulate LCFA was confirmed by microscopic observation of a sludge that had been in prolonged contact with oleic acid under continuous operation mode (Figs. 2 and 3).

In this sludge, clear whitish zones can be identified, likely representing the LCFA associated with the biomass (Fig. 2a,b). These white zones seem to act as a light emission barrier, decreasing the visible $420-\mathrm{nm}$ autofluorescence of the methanogenic population (Fig. 2c,d). Scanning electron micrographs allowed observing a net difference on the sludge aspect before and after being loaded with oleic acid (Fig. 2e,f). In the later case, the presence of a nonbiologic matrix entrapping the microorganisms is suggested, and a crystalline structure can also be clearly identified (Fig. 2a,f,g,h).

Sudan black staining confirmed the presence of lipid matter in the sludge after it been loaded with oleic acid (Fig. 3a,b). This lipid material, which is stained as a blue/ black color, was not detected in the sludge after the mineralization of the biomass-associated LCFA (Fig. 3c) or when the sludge was submitted to the control procedure for lipid removal (Fig. 3d). It is also interesting to note that the counterstaining of the cells with safranin was significantly more evident in the sludge without LCFA than in the sludge loaded with LCFA. Adsorption of LCFA onto the cell surface may impair cell staining, justifying this observation.

The anaerobic sludge structure was previously found to be important for the phenomenon of LCFA mineralization, suspended sludge, small fluffy and filamentous flocs, being more efficient for LCFA accumulation and degradation than granular sludge (Pereira et al., 2002). The localization of lipid matter inside the loose floc structure may justify the large amounts of LCFA that can be entrapped by this type of sludge compared to the dense granular sludge. From these microscopic observations is evidenced the important contribution of precipitation and entrapment on LCFA accumulation.

\section{Kinetics of Biomass-Associated LCFA Degradation}

LCFA accumulation onto the anaerobic sludge was previously found to be important as a way to promote its mineralization, but the conditions that allow the optimal conversion to methane were not yet defined. When the 38 sludge samples were individually incubated in batch vials without any added organic carbon source, calcium, or nutrients, methane was produced due to the mineralization of the LCFA that had accumulated onto the sludge. The specific methane production rate and the amount of the biomass-associated LCFA per VSS unit (specific LCFA content) were calculated for each sample, as exemplified in Figure 1, and are plotted in Figure 4. This graph represents the influence of the available substrate on the kinetics of its own mineralization. It is not a conventional kinetic plot, as the substrate is not dissolved in the medium but instead is associated with the sludge. In spite of that, experimental data were fitted by Eq. (1), which represents an adaptation of an inhibition model used before by Andrews (1971) to describe the inhibition of volatile fatty acids in the 

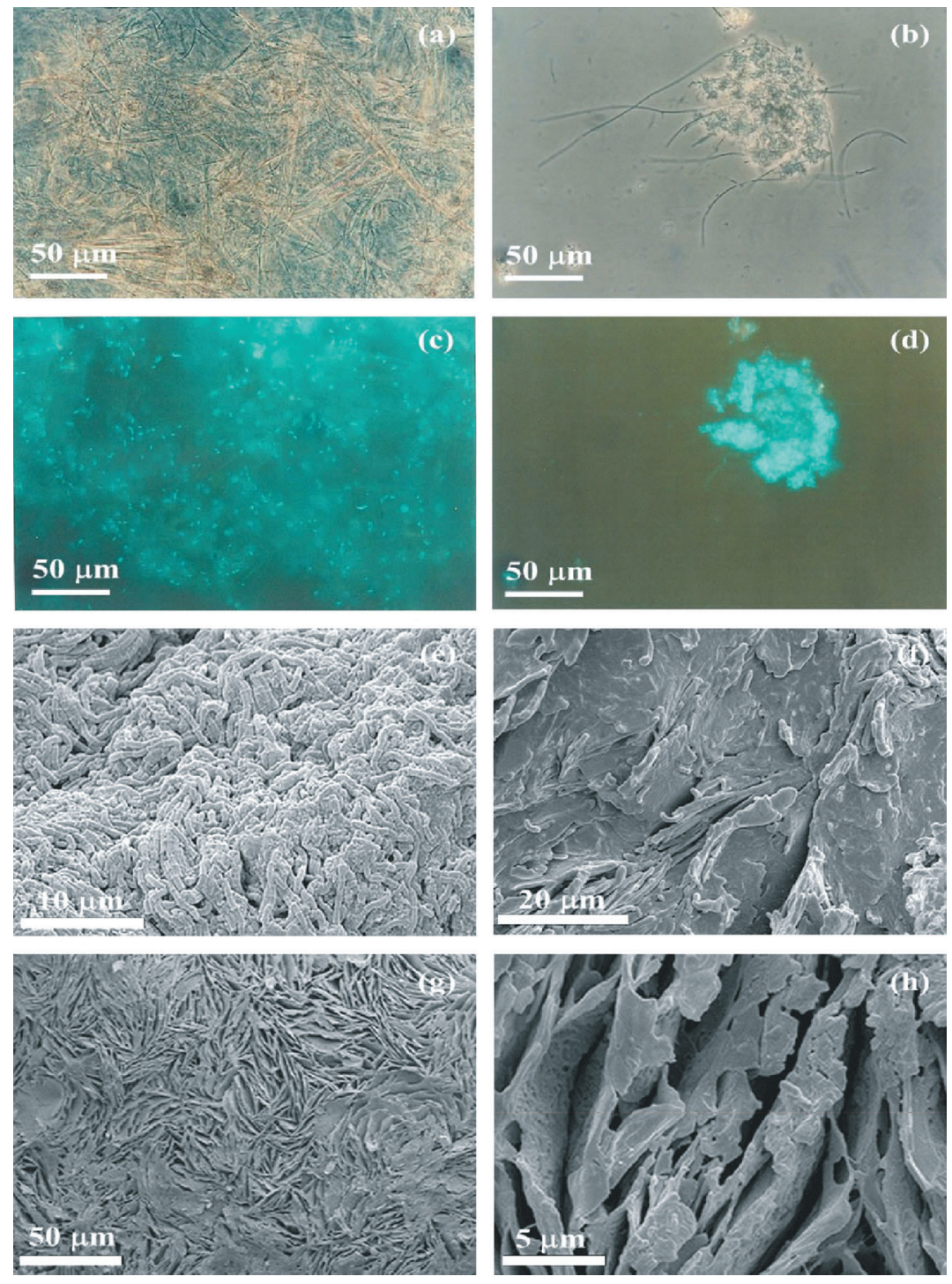

Figure 2. Microscopic aspects of the anaerobic sludge loaded with oleic acid. Whitish zones (a,b) seem to decrease the visible $420 \mathrm{~nm}$ auto-fluorescence $(\mathbf{c}, \mathbf{d})$. Sludge before (e) and after (f) being loaded with LCFA, and evidence of a crystalline structure in a loaded sludge (g,h).

anaerobic digestion process. This model is based on the substrate inhibition enzymatic kinetics developed by Haldane (1930).

$$
q_{\mathrm{p}}=\frac{\hat{q}_{\mathrm{p}} \times S_{\mathrm{ba}}}{K_{\mathrm{S}}+S_{\mathrm{ba}}+\frac{S_{\mathrm{ba}}^{2}}{K_{i}}},
$$

where $q_{\mathrm{p}}$ is the specific methane production rate $\left[M_{\text {substrate }} \cdot M_{\text {biomass }}{ }^{-1} \cdot t^{-1}\right], S_{\text {ba }}$ is the biomass-associated substrate per VSS unit $\left[M_{\text {substrate }} \cdot M_{\text {biomass }}{ }^{-1}\right]$, and $\hat{\mathrm{q}}_{\mathrm{p}}, K_{\mathrm{S}}$, and $K_{i}$ are model parameters.

Table II summarizes the results obtained by the fitting as well as the corresponding correlation coefficient, determined by the Levenberg-Marquardt method (Marquardt, 1963).

Based on this model, a value of 1,080 mg COD-LCFA.g $\mathrm{VSS}^{-1}$ was found to be the critical biomass-associated substrate per VSS unit $\left(S_{\mathrm{ba}}^{\text {crit }}\right)$, which leads to the maximal mineralization rate, found to be $250 \mathrm{mg}$ COD- $\mathrm{CH}_{4} \cdot \mathrm{g}$ $\mathrm{VSS}^{-1} \cdot \mathrm{day}^{-1}$ (Eq. (2)).

$$
S_{\mathrm{ba}}^{\mathrm{crit}}=\sqrt{K_{\mathrm{S}} K_{i}}
$$

The low correlation coefficient obtained for the fit (0.56) imposes a significant uncertainty on the value of $S_{\mathrm{ba}}^{\text {crit }}$. Therefore, a value around 1,000 $\mathrm{mg}$ COD-LCFA.g VSS ${ }^{-1}$ represents just a rough estimate of the specific LCFA load that allows the maximal mineralization rate of the biomassassociated LCFA. However, even with precision limitations, it has practical interest as far as the mineralization of LCFA is concerned.

The low correlation coefficient obtained by this fitting also suggests that the mechanism of inhibition is more complex than a simple substrate inhibition phenomenon, in 


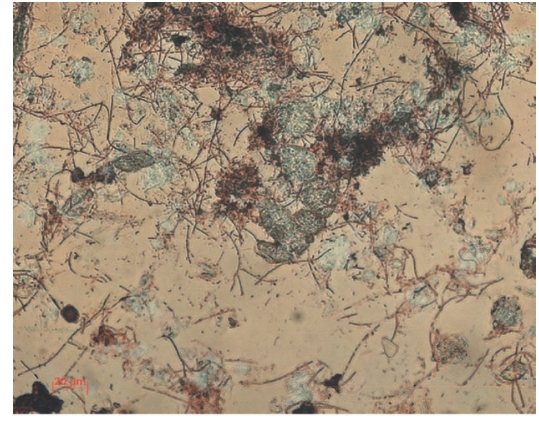

(a)

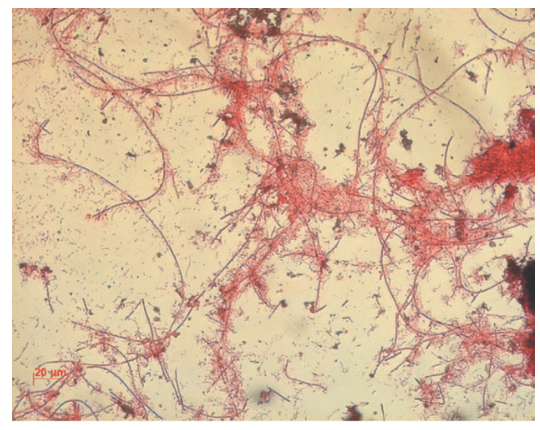

(c)

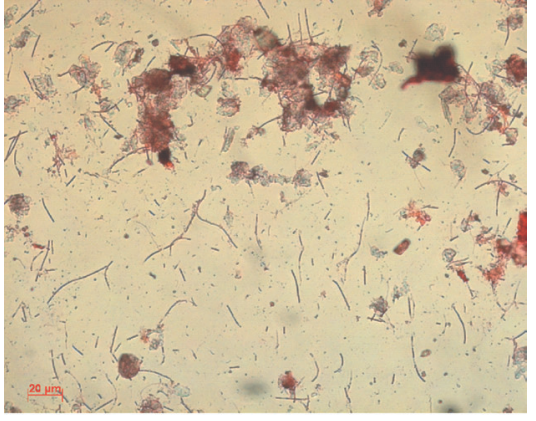

(b)

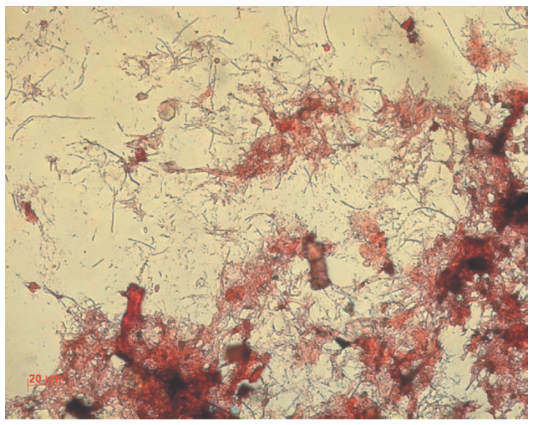

(d)

Figure 3. Sudan black B staining of a sludge containing biomass-associated LCFA (a,b) and after mineralization of these biomass-associated compound (c). The same staining was applied to the sludge after being submitted to the lipids removal procedure (d). Blue/black-color staining, lipid matter; red color, counterstaining.

part because the $\beta$-oxidation process involves a sequence of substrates and products that can compete with each other. Furthermore, the method used to measure the amount of the accumulated substrate is based on the measurement of the final product (methane) and thus depends on the metabolic activity of different trophic groups in the consortium. On the other hand, as previously suggested by Pereira et al. (2003), transport limitations may have an important role on LCFA mineralization. As the LCFA seems to be mostly in

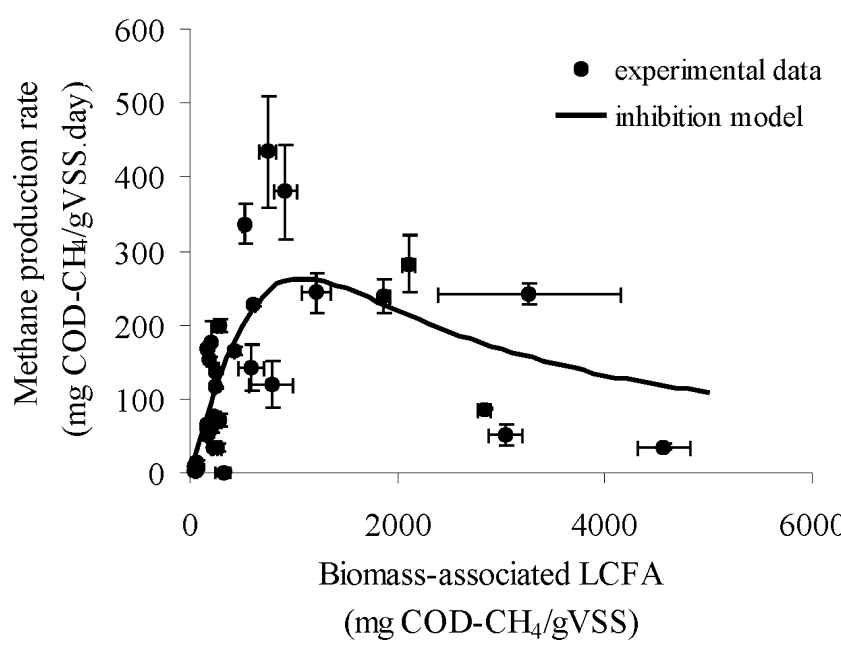

Figure 4. Kinetics of methane production in batch assays due to the degradation of the biomass-associated LCFA. Bars represent the standard deviation. intimate contact with the biomass, substrate diffusion limitations are not expected to limit the degradation rate, but product diffusion limitation, e.g., biogas release, can be hampered by the LCFA associated with the sludge and thus may induce a delay on the measured methane production. This is not taken into account in the inhibition model and may also contribute to the relative discrepancy between model prediction and experimental data.

\section{Enhancement of Specific Methanogenic Activity After the Mineralization of the Biomass-Associated LCFA}

The use of an inhibition model to fit the experimental data suggests a decrease in the consortium capacity to mineralize specific LCFA contents above about 1,000 mg COD.g $\mathrm{VSS}^{-1}$. This decrease may be due to a metabolic or a physical inhibition (transport limitations), as previously suggested by Pereira et al. (2003). Whatever the phenomenon that is behind the inhibition (metabolic or physical), it is important to evaluate if it is reversible. In order to obtain

Table II. Kinetic constants for the applied inhibition model.*

\begin{tabular}{lc}
\hline$\hat{q}\left(\mathrm{mg} \mathrm{COD}-\mathrm{CH}_{4} \cdot \mathrm{g} \mathrm{VSS}^{-1} \cdot \mathrm{day}^{-1}\right)$ & 384,361 \\
$K_{\mathrm{S}}\left(\mathrm{mg} \mathrm{COD}-\mathrm{CH}_{4} \cdot \mathrm{g} \mathrm{VSS}^{-1}\right.$ & 790,495 \\
$K_{i}\left(\mathrm{mg} \mathrm{COD}-\mathrm{CH}_{4} \cdot \mathrm{g} \mathrm{VSS}^{-1}\right.$ & 1.48 \\
Correlation coefficient & 0.56
\end{tabular}

*Based on Haldane's enzymatic kinetics (Haldane, 1930). 


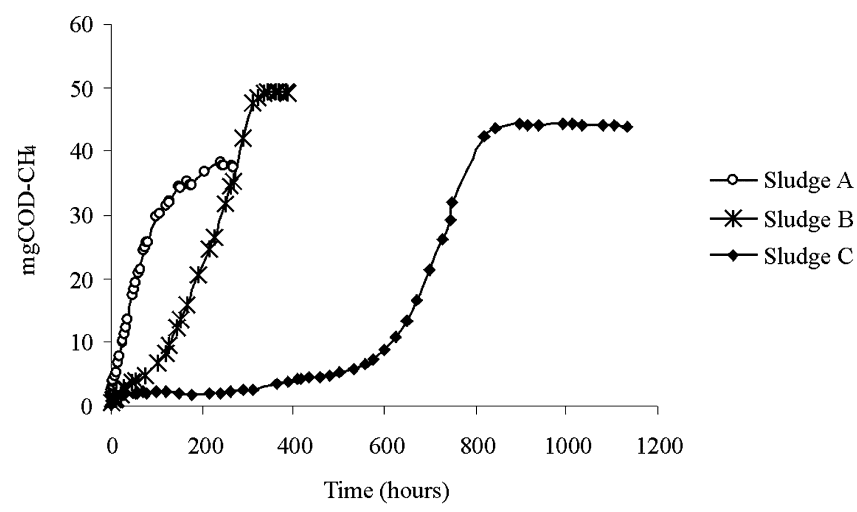

Figure 5. Cumulative methane production due to the mineralization of the biomass-associated LCFA. Each curve represents an average of three replicates. Sludges A, B, and C have specific LCFA contents of 1,221 \pm $144,2,838 \pm 63$, and 4,571 $\pm 257 \mathrm{mg} \mathrm{COD}-\mathrm{CH}_{4} \cdot \mathrm{g} \mathrm{VSS}^{-1}$, respectively.

more insight on this aspect, three sludge samples containing specific LCFA contents in the range of $1,000-5,000 \mathrm{mg}$ COD.g VSS ${ }^{-1}$ were studied in terms of the methanogenic activity in the presence of individual substrates (acetate, propionate, butyrate, and $\mathrm{H}_{2} / \mathrm{CO}_{2}$ ) before and after the depletion of the biomass-associated LCFA. Figure 5 represents the cumulative methane production when each sludge sample was incubated in batch assays without any added organic source.

The specific LCFA contents associated with each sludge, obtained by dividing the maximum plateaux by the amount of VSS present at the end of each experiment were, on average, $1,221 \pm 144,2,838 \pm 63$, and 4,571 $\pm 257 \mathrm{mg}$ COD.g VSS ${ }^{-1}$. The corresponding specific methane production rates were, in average, $243 \pm 28,87 \pm 2$, and $35 \pm$ $4 \mathrm{mg} \mathrm{COD}-\mathrm{CH}_{4} \cdot \mathrm{g} \mathrm{VSS}^{-1} \cdot \mathrm{day}^{-1}$. In the sludge with a lower specific LCFA content (sludge A), no lag phase was observed preceding the initial methane production, whereas in sludges B and C, lag phases around 100 and $500 \mathrm{~h}$, respectively, were detected, which were traduced by a low value in terms of initial methane production rate. However, after these delays, methane production proceeded at rates

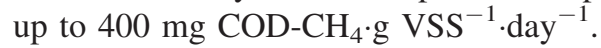

Samples A, B, and C were characterized in terms of the SMA with acetate, propionate, butyrate, and $\mathrm{H}_{2} / \mathrm{CO}_{2}$, before and after allowing the mineralization of the biomassassociated LCFA. Table III summarizes the obtained results.

In the experiment before allowing the mineralization of the biomass-associated LCFA, the less loaded sludge, i.e., sludge $\mathrm{A}$, exhibited a measurable specific activity in acetate, butyrate, $\mathrm{H}_{2} / \mathrm{CO}_{2}$, but no activity with propionate as substrate. Sludge $\mathrm{B}$ and $\mathrm{C}$ presented no initial SMA, except with $\mathrm{H}_{2} / \mathrm{CO}_{2}$ as substrate. After the mineralization of the biomass-associated LCFA, an increase on the SMA in the range of specific LCFA contents between 1,000 and $5,000 \mathrm{mg} \mathrm{COD} \cdot \mathrm{g} \mathrm{VSS}^{-1}$ was observed for all the selected substrates. With the single exception of the SMA with hydrogen as substrate, the difference between the activities measured before and after the mineralization of the accumulated substrate was maximal for the sludge $\mathrm{B}$, which has a specific LCFA content of $2,838 \mathrm{mg}$ COD.g VSS ${ }^{-1}$.

This result proves that the effect of LCFA in the decrease of the SMA, is a reversible phenomenon in the range of specific LCFA content between 1,000 and 5,000 mg COD.g $\mathrm{VSS}^{-1}$. This is a remarkable result that clearly contradicts the bactericidal or permanent toxic effects of LCFA, previously reported by Rinzema (1988) and by Angelidaki and Ahring (1992), and creates a new challenge for the anaerobic treatment of wastes/wastewater with high lipid contents.

The low or null SMA measured before the depletion of the biomass-associated LCFA may result from a strong effect of transport (diffusion) limitations imposed by the LCFA layer surrounding the cells, which could hamper the access of the added substrates, as well as the subsequent biogas release. This is reinforced by the fact that $\mathrm{H}_{2}$, the smallest substrate used, was, in all cases, easily mineralized to methane, suggesting a fast transport of this molecule through the LCFA layer. Transport limitations phenomena may be responsible by the observed lag phases that have been ascribed to mechanisms of cell wall damage and bactericidal effects, widely accepted for years. The recovery after a lag phase, attributed to the growth of few survivors (Rinzema, 1988), could be a delay imposed by transport limitations. However, although the hypothesis of

Table III. Specific methanogenic activities exhibited by sludges A, B, and C, before and after mineralization of biomass-associated LCFA.

\begin{tabular}{|c|c|c|c|c|c|c|}
\hline \multirow[b]{3}{*}{ In the presence of } & \multicolumn{6}{|c|}{ Specific methanogenic activity (mg COD-CH.g VSS ${ }^{-1} \cdot$ day $^{-1}$ ) } \\
\hline & \multicolumn{2}{|c|}{ Sludge A } & \multicolumn{2}{|c|}{ Sludge B } & \multicolumn{2}{|c|}{ Sludge C } \\
\hline & Before $^{a}$ & After $^{\mathrm{b}}$ & Before $^{\mathrm{a}}$ & After $^{\mathrm{b}}$ & Before $^{\mathrm{a}}$ & After ${ }^{\mathrm{b}}$ \\
\hline Acetate & $143 \pm 29$ & $326 \pm 13$ & 0 & $579 \pm 4$ & 0 & $533 \pm 95$ \\
\hline Propionate & 0 & $43 \pm 2$ & 0 & $25 \pm 1$ & 0 & $16 \pm 5$ \\
\hline Butyrate & $102 \pm 28$ & $146 \pm 6$ & 0 & $646 \pm 9$ & 0 & $224 \pm 71$ \\
\hline $\mathrm{H}_{2} / \mathrm{CO}_{2}$ & $1,462 \pm 94$ & $1,670 \pm 81$ & $1,218 \pm 1$ & $2,817 \pm 146$ & $401 \pm 21$ & $2,709 \pm 38$ \\
\hline
\end{tabular}

${ }^{\mathrm{a}}$ Methane production rates of $243 \pm 28,87 \pm 2$, and $35 \pm 4 \mathrm{mg} \mathrm{COD}-\mathrm{CH}_{4} \cdot \mathrm{g} \mathrm{VSS}^{-1} \cdot \mathrm{day}^{-1}$ (blank assays) were discounted in the assessment of the SMA in sludges A, B, and C, respectively.

${ }^{\mathrm{b}}$ Background methane production rates (blank assays) were null. 
transport limitations seems to be reasonable, there is no absolute sureness of it, because if LCFA exerted a reversible inhibitory effect, the result could be similar. Probably both phenomena are involved, its dominance depending on the specific LCFA content of the sludge.

Before the depletion of the biomass associated LCFA, sludges $B$ and $C$ presented null SMA values with the tested VFA because the initial methane production was lower than the one measured for the blank controls. Figure 6 shows the initial methane production pattern obtained during the SMA measurement in sludge B, exemplifying this behavior.

A similar effect was also previously observed when oleic acid was added, inducing a severe delay in the mineralization of the biomass-associated LCFA (Pereira et al., 2002).

These results suggest that optimal conditions for LCFA mineralization occur in the absence of organic carbon in the bulk medium. However, the presence of other organic carbon sources in the medium, for instance VFA, is highly expected in any real anaerobic digestion process.

Sludge A, which contains a specific LCFA content near the optimal value (determined according to the kinetic model), was selected to more deeply evaluate the interactions between individual VFA externally added (acetate, propionate, and butyrate) and the mineralization of the biomass-associated LCFA. The choice of this sludge was based on the practical interest of a better understanding of the role of VFA in the conditions that allow the optimal mineralization of the accumulated LCFA.

\section{Effect of Acetate, Propionate, and Butyrate on the Mineralization of the Biomass-Associated LCFA}

Figure 7 presents the methane production and VFA depletion when sludge $\mathrm{A}$ is characterized in terms of SMA with acetate, propionate, or butyrate. Individual VFA were also monitored during the mineralization of the biomassassociated LCFA ("blank" assay), which revealed that, in

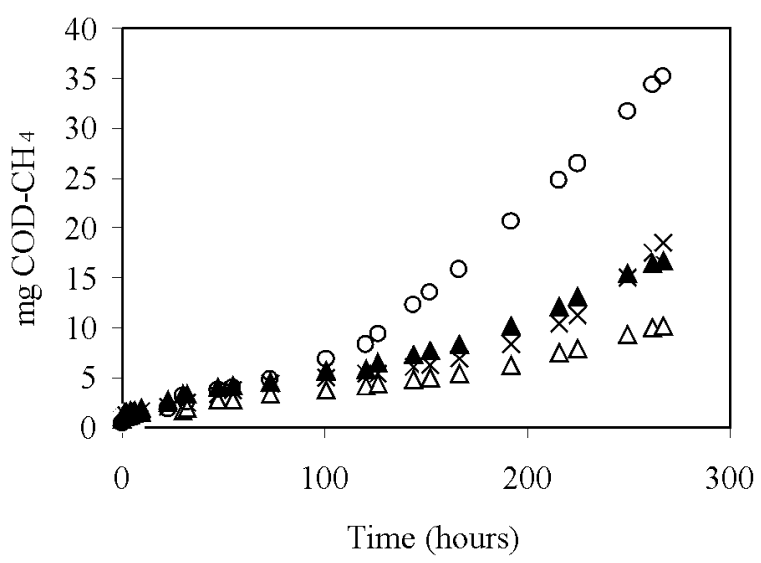

Figure 6. Initial methane production during the methanogenic activity measurement of sludge $\mathrm{B}$ (before the mineralization of the biomassassociated LCFA) with the addition of acetate $(\times)$, propionate $(\triangle)$, and butyrate $(\boldsymbol{\Delta})$ as individual substrates, and in the blank control assay $(\mathrm{O})$.
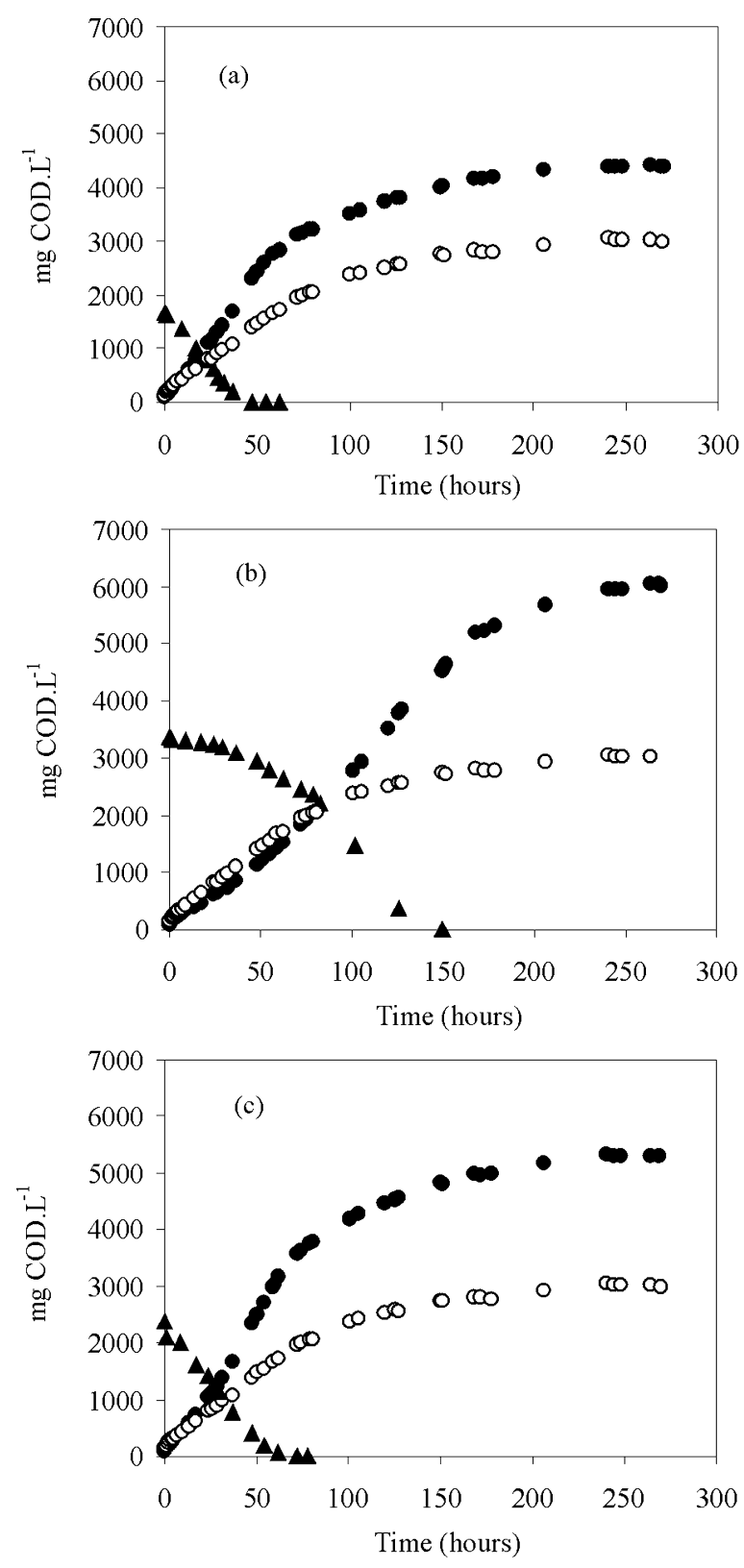

Figure 7. Time course of methane production and VFA depletion in the batch assays performed with sludge A, when acetate (a), propionate (b), and butyrate (c) were added. (O) Methane production due to the degradation of the biomass-associated LCFA and the added VFA, (O) methane production due to the degradation of the biomass-associated LCFA, and ( $\Delta$ ) total VFA depletion in the medium.

these conditions, there was no detectable release of VFA to the medium. This was assumed to prevail also in the test vials. During propionate degradation, acetate and butyrate were detected in concentrations not exceeding 140 and $74 \mathrm{mg} / \mathrm{L}$, respectively. Acetate was also detected during butyrate degradation, in concentrations lower than $170 \mathrm{mg} / \mathrm{L}$.

In order to allow direct comparison with the corresponding methane production, VFA depletion rates were calculated taking into account the total VFA present in the medium and were expressed as COD. As different working 
Table IV. Comparison between specific activities of a sludge with a LCFA content of 1,221 $\pm 144 \mathrm{mg}$ COD.g VSS ${ }^{-1}$, with measured VFA depletion and methane production (mean $\pm \mathrm{SD}$ ).

\begin{tabular}{|c|c|c|}
\hline $\begin{array}{l}\text { Specific activity in } \\
\text { the presence of }\end{array}$ & $\begin{array}{l}\text { VFA depletion } \\
\text { rate mg COD-VFA.g } \\
\operatorname{VSS}^{-1} \cdot \text { day }^{-1}\end{array}$ & $\begin{array}{c}\mathrm{CH}_{4} \text { production rate } \\
\mathrm{mg} \mathrm{COD}-\mathrm{CH}_{4} \cdot \mathrm{g} \\
\mathrm{VSS}^{-1} \cdot \text { day }^{-1}\end{array}$ \\
\hline Acetate & $362 \pm 3$ & $387 \pm 8$ \\
\hline Propionate & $47 \pm 5$ & $172 \pm 11$ \\
\hline Butyrate & $359 \pm 13$ & $345 \pm 6$ \\
\hline $\begin{array}{l}\text { Blank controls } \\
\quad(\text { no added substrate })^{\mathrm{b}}\end{array}$ & $(\text { n.d })^{\mathrm{c}}$ & $244 \pm 27$ \\
\hline
\end{tabular}

${ }^{\mathrm{a} W i t h o u t ~ d i s c o u n t i n g ~ t h e ~ p r o d u c t i o n ~ o f ~ t h e ~ b l a n k ~ c o n t r o l s . ~}$

b"Blank control" correspond to the mineralization of the biomassassociated LCFA.

${ }^{c}$ n.d. non-detectable VFA in the medium.

volumes were used in the gas and liquid assays, all the values were expressed per volume unit.

Table IV summarizes the results obtained for the specific methanogenic activity of the sludge A, measured by VFA depletion and $\mathrm{CH}_{4}$ production.

From the results obtained, it can be observed that, when acetate was added to the LCFA-loaded sludge (Fig. 7a), the initial methane production was due mainly to the consumption of the added acetate because the acetate depletion rate was similar to the corresponding methane production (Table IV). A similar pattern was observed when the added VFA was butyrate (Fig. 7c), but different behavior was observed for propionate (Fig. 7b). The VFA concentration decreased only $10 \%$ in the first $50 \mathrm{~h}$, whereas in the same time period, $99.1 \%$ and $83.6 \%$ of total VFA disappeared from the medium when acetate and butyrate were added, respectively. Furthermore, in the presence of propionate, the initial specific methane production rate was significantly lower than in the situation where the mineralization of the biomass-associated LCFA was monitored (Fig. 7b; Table IV). In the former situation, methane production seems to be a result of the interaction between both substrates (propionate + LCFA) degradation, because there was no evidence of a sequential consumption pattern.

\section{CONCLUSIONS}

The results presented in this work point out new insights on the anaerobic biodegradation of biomass-associated LCFA. It is important to highlight the sludge ability to mineralize biomass-associated LCFA up to specific contents of $5,000 \mathrm{mg}$ COD-LCFA.g VSS ${ }^{-1}$ as well as the enhancement of sludge activity after the LCFA mineralization.

The mineralization kinetics of the LCFA associated to the sludge was established and a specific content of about $1,000 \mathrm{mg}$ COD-LCFA.g VSS ${ }^{-1}$ was found to be the optimal for an efficient methane production rate.

For sludge loaded with a LCFA specific content near the optimal value, the presence of acetate, propionate, or butyrate (with acetate and propionate at $30 \mathrm{mM}$ and butyrate at $15 \mathrm{mM}$ ), did not impair the process as no delay was observed in terms of overall methane production.

From a practical viewpoint, the results presented herein clearly support the approach of using sequential accumulation and degradation steps for the treatment of lipid/ LCFA-based effluents.

The authors acknowledge the Fundação para a Ciência e Tecnologia (FCT) and Fundo Social Europeu (FSE) for the financial support given to M.A. Pereira (PRAXIS XXI/BD/20326/99) and D.Z. Sousa (SFRH/BD/8726/2002). The support of Ana Margarida Coelho in the staining procedure is gratefully acknowledged.

\section{References}

Alves MM, Bellouti M, Pereira MA, Álvares Pereira MR, Mota Vieira JA, Novais JM, Mota M. 1998. A new method to study interactions between biomass and packing material in anaerobic filters. Biotechnol Techn 12:277-283.

Alves MM, Mota Vieira JA, Álvares Pereira RM, Pereira MA, Novais JM, Mota M. 2001. Effects of lipids and oleic acid on biomass development in anaerobic fixed bed reactors. Part I: Biofilm growth and activity. Water Res 35:255-263.

American Public Health Association; American Water Works Association; and Water Pollution Control Federation. 1989. Standard Methods for the Examination of Water and Wastewater. 17th edition. Washington, DC: APHA, AWWA, WPCF.

Andrews JF. 1971. Kinetic models of biological waste treatment processes. Biotechnol Bioeng 2:5-33.

Angelidaki I, Ahring BK. 1992. Effects of free long-chain fatty acids on thermophilic anaerobic digestion. Appl Microbiol Biotechnol 37: $808-812$.

Beccari M, Majone M, Torrisi L. 1998. Two-reactor system with partial phase separation for anaerobic treatment of olive oil mill effluents. Water Sci Tech 38:387-394.

Cavaleiro AJ, Alves MM, Mota M. 2001. Microbial and operational response of an anaerobic fixed bed digester to oleic acid overloads. Proc Biochem 37:387-394.

Coates JD, Coughlan MF, Colleran E. 1996. Simple method for the measurement of the hydrogenotrophic methanogenic activity of anaerobic sludges. J Microbiol Methods 26:237-246.

Colleran E, Concannon F, Goldem T, Geoghegan F, Crumlish B, Killilea E, Henry M, Coates J. 1992. Use of methanogenic activity tests to characterize anaerobic sludges, screen for anaerobic biodegradability and determine toxicity thresholds against individual anaerobic trophic groups and species. Water Sci Technol 25:31-40.

Demeyer DI, Henderickx HK. 1967. The effect of $\mathrm{C}_{18}$ unsaturated fatty acids on methane production in vitro by mixed rumen bacteria. Biochim Biophys Acta 137:484-497.

Dolfing J, Bloemen WGBM. 1985. Activity measurements as a tool to characterize the microbial composition of methanogenic environments. J Microbiol Methods 4:1-12.

Galbraith H, Miller TB, Paton AM, Thompson JK. 1971. Antibacterial activity of long chain fatty acids and reversal with calcium, magnesium, ergocalciferol and cholesterol. J Appl Bacteriol 34: 803-813.

Haldane JBS. 1930. Enzymes. London, UK: Longmans, Green.

Hamdi M, Festino C, Aubart C. 1992. Anaerobic digestion of olive mill wastewaters in fully mixed reactors and in fixed film reactors. Proc Biochem 27:37-42.

Hawkes FR, Donnely T, Anderson GK. 1995. Comparative performance of anaerobic digesters operating on ice-cream wastewater. Water Res 29:525-533.

High OB. 1984 Lipid histochemistry. Royal Microscopical Society microscopy handbooks. Vol. 6. New York: Oxford University Press. 
Hwu C-S. 1997. Enhancing anaerobic treatment of wastewater containing oleic acid. Ph.D. thesis. Wageningen, The Netherlands: Wageningen Agricultural University.

Komatsu T, Hanaki K, Matsuo T. 1991. Prevention of lipid inhibition in anaerobic processes by introducing a two-phase system. Water Sci Technol 23:1189-1200.

Koster IW, Cramer A. 1987. Inhibition of methanogenesis from acetate in granular sludge by long-chain fatty acids. Appl Environ Microbiol 53:403-409.

Lalman JA, Bagley DM. 2001. Anaerobic degradation and methanogenic inhibitory effects of oleic and stearic acids. Water Res 35:2975-2983.

Marquardt JD. 1963. An algorithm for least-squares estimation of nonlinear parameters. J Soc Ind Appl Math 11:431-441.

Pereira MA, Cavaleiro AJ, Mota M, Alves MM. 2003. Accumulation of LCFA onto anaerobic sludge under steady state and shock loading conditions: effect on acetogenic and methanogenic activity. Water Sci Technol 48:33-40.

Pereira MA, Pires OC, Mota M, Alves MM. 2002. Anaerobic degradation of oleic acid by suspended and granular sludge: identification of palmitic acid as a key intermediate. Water Sci Technol 45:139-144.

Rinzema A. 1988. Anaerobic treatment of wastewater with high concentration of lipids or sulfate. Ph.D. thesis. Wageningen, The Netherlands: Wageningen Agricultural University.

Salminen E, Einola J, Rintala J. 2001. Characterization and anaerobic batch degradation of materials accumulating in anaerobic digesters treating poultry slaughterhouse waste. Environ Technol 22(5):577-585.

Samson R, Van den Berg B, Peters R, Hade C. 1985. Dairy waste treatment using industrial-scale fixed-film and upflow sludge bed anaerobic digesters: design and start-up experience. In: Bell JM, editor. Proceedings of the 39th Purdue Industrial Waste Conference. Boston: Butterworth Publ. p 235-241.

Sam-soon P, Loewenthal RE, Wentzel MC, Marais GvR. 1991. A longchain fatty acid, oleate, as sole substrate in upflow anaerobic sludge bed (UASB) reactor systems. Water SA 17:31-36.

Seviour RJ, Blackall LL. 1999. The microbiology of activated sludge. London: Kluwer Academic Publishers. 